\title{
Self-Employment in the Cultural and Educational Sphere as the Principle in Human Capital Development
}

\author{
${ }^{1}$ Kalmyk State University, Russia \\ ${ }^{2}$ Financial University under the Government of the Russian Federation, Russia \\ ${ }^{3}$ Lomonosov Moscow State University, Russia \\ *Email: esb0001@mail.ru
}

Elizaveta Boldyreva $^{1, *}$, Baina Dordzhieva ${ }^{2}$, Elzata Boldyreva ${ }^{3}$, Olga Dordzhieva ${ }^{1}$

\begin{abstract}
This publication reveals a solution of the problem concerning identification and definition of the role, place, and effective use of self-employed persons' labour activity within the context of studying the issue of human capital development in an agricultural region. A special form of employment requires unifying the government regulation of their activities. This article presents the results of studying self-employed freelancers' activity - self-made rendering cultural and educational services to children and receivers themselves of these services (parents and children). The interpretation of obtained results made it possible to develop recommendations on refining the policy in this sphere and define hot topics of follow-up studies. Based on the analysis of main solutions, conclusions of carried out measures on the discussion of the obtained results in the form of foresight - sessions, round-tables, conferences, the recommendation was developed for this group of self-employed persons on developing the self-regulation institution excluding the formed gap concerning the definition of the business ethics rules, as well as other issues concerning this special form of employment to avoid the excessive regulation.
\end{abstract}

Keywords: Freelancer, Self-employed persons, Form of employment, Self-made.

\section{INTRODUCTION}

According to calls of the time and society, the modern development of the socio-economical environment brings into our reality the new forms of rendering services that serve as the new forms of employment. The Report of the Centre of labour research and the Laboratory of labour-market research of NRU HSE "The Russian labour market: trends, institutes, structural changes", dated 2017, points out that the increasing deformalisation of employment has become a specific feature of the modern Russian labour market model. Its distinctive feature serves as unregulated or weakly regulated micro-business [1, p.148].

From the speech of director of All-Russian Research and Development Institute of Labour Dmitry Platygin, the active development of new forms of employment with steady growth dynamics is associated with several risks' participants. In the absence of sufficient business activity experience, tax remission, when income is low and unstable, is problematic, and open social security points occur. But at the same time, "...in the public perception, this form of employment is associated with a positive state of mind and will trend to develop". The great majority of those who wish to do business is the young population, and it is this category expresses readiness for non-standard forms of employment [2].

The popularity of any activity type depends on features of regional preferences and needs of service customers and receivers. In the Republic of Kalmykia, cultural and educational services for children are in great demand (qualifying requirement of Kalmyk community both now and always was and is sufficiently high, the demand of society for the special level of this particular type of services is expectable), social services associated with a healthy lifestyle, beauty, etc. As a general principle, the Republic of Kalmykia's economy is characterised by "the prevalence of traditional forms of the economic activity, the use of handicrafts, home-based 
labour, low social and spatial mobility of the population" [3, p.547-549].

In this context, the study of the above phenomenon receives a special actuality and priority in two aspects: the growing special form of employment of the population as an element of the modern economic and social system and the quality of its services in the cultural and educational sphere as the assumption for the development of human capital. The methodological basis of the assessment of investment performance into human capital was formed by conceptual approaches of $\mathrm{T}$. Schulz, Y. Ben-Porath. In their studies, they consider the development of human capital due to the implementation of personal expenses [4, p.272], [5, p.58-72].

\section{RESEARCH METHODOLOGY}

Foresight technologies in the research were chosen as the basis of methodological approach which during active participation of all major stakeholders in the discussion of problematic issues, investigation of variants of their solution allowed a wide expansion for foresight area itself and the growth of civic culture (sessions, roundtables).

Express-survey used in solving the designated tasks allows us to consider together the respondent population and the evaluated process, the effective use of the polling time in obtaining the results for taking the proper management solutions timely.

For studying the various aspects of the human capital development, Pedagogical school of Kalmyk State University, faculty of economics, during the period from September to November 2019 carried out several express-survey concerning economic activity agents in the field of rendering services to children. The opinion of participants in this process was studied by the polling method. Survey of children in schools, students, parents of children visiting art and craft rooms, people, and selfemployed freelancers engaged in arranging the studio activity was carried out. The study's purpose involved the research of the self-employment phenomenon itself in this field, problems and prospects for further developing this tendency as one of the conditions of human development in the agricultural region. Respondents expressed their attitude to studio-section classes for children implemented by self-employed subjects, the influence of classes in studios on the formation of personal qualities. An attempt was made to clarify the purposes of defining interests in this sphere and identify both consumers and service promoters' problematic aspects.

In total, 719 respondents took part in the survey:

- In studying the popularity and usefulness of activities of self-employed freelancers in the field of rendering the cultural and educational services to children, 240 respondents were polled;

- 92 respondents were polled when studying the attitude of country inhabitants to the activity of selfemployed freelancers;

- 387 respondents were polled when studying the attitude of parents to the activity of self-employed freelancers.

Carried out investigations make it possible to rightfully argue that today the rather significant sector of subjects involved in the sphere of cultural and educational services rendered to children has been formed in the Republic of Kalmykia.

\section{RESULTS}

\section{1. of studying the popularity and usefulness of activity of self-employed freelancers}

240 respondents were surveyed, among them: 62 students aged 18 to 21,122 schoolchildren aged 15 to 17 and 56 adults aged 22 to 65 .

According to obtained data, when asked "whether you visit the cultural and educational section", 59\% of respondents replied in the positive (yes, with pleasure without passes, spontaneously), 19\% answered (yes, but at the insistence of elders, without desire, passes took place) and $22 \%$ answered: not. (see. Fig. 1).

\section{Have you attended cultural and educational sections?}

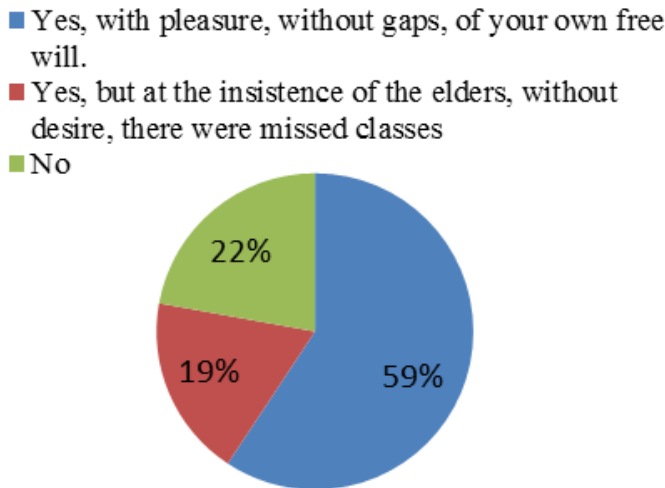

Figure 1 Visit of sections by respondents.

When asked "Whether your young relatives visit cultural and educational sections", most of the respondents $(64 \%)$ answered "visit sections with pleasure", $20 \%$ - visit at the insistence of elders and $16 \%$ of respondents do not visit the sections [7, p.33-35].

When asked "whether the attended sections affect the formation of personality" (see fig. 2), $43 \%$ of respondents answered that affect if are selected for the development of data given from birth and based on the child's interest, $42 \%$ - affect because they develop skills significant for 
life, and rest $15 \%$ believe that affect because they deflect from the negative.

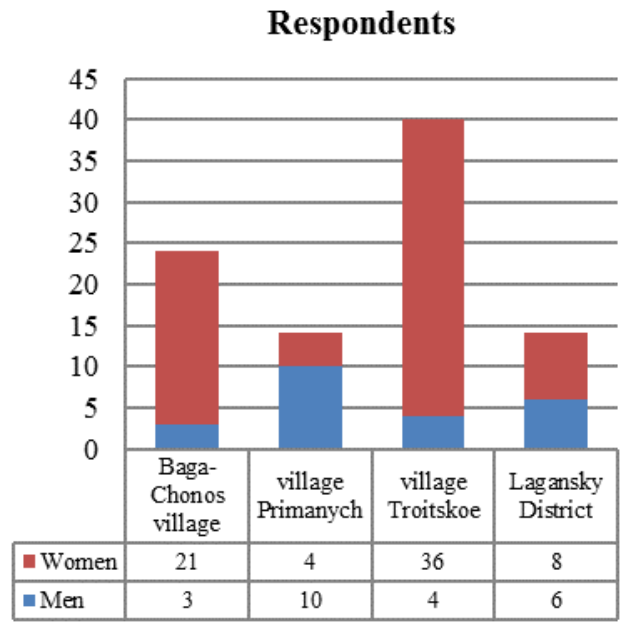

Figure 2 Composition of respondents at the place of the survey of the peasant population.

When asked "What is the importance of these sections?", $49 \%$ of respondents answered that they affect the general formation and development of personality, $27 \%$ develop skills obtained from specialists and rest $24 \%$ - socialisation in the particular sphere, forming special interests.

Thus, the carried-out survey showed that about $80 \%$ of respondents used this type of services. The same tendency remains concerning their younger relatives.

$100 \%$ of respondents consider that studio-section classes are useful, essential, and necessary to form the human potential and positively influence personality development.

\subsection{The study of the attitude of country inhabitants to the activity of self-employed freelancers}

In terms of the express-study "Implementation of cultural and educational projects of self-employment as a factor of the personality formation", the peasant population's survey was carried out. 92 of village residents of the Republic of Kalmykia's districts (69 women and 23 men) (see Fig. 3).

The influence of the residency remoteness on the attendance of sections is the fact that there is a little of sections in the rural regions (the answer of $57 \%$ of men and $84 \%$ of women, which is $72 \%$ of the total number of respondents), only $17 \%$ of men and $6 \%$ of women have no problems with roads, which is about $9 \%$ of the total number of respondents. Although there are roads, difficulties of other nature are present (time, costs), so evolving problems are resolvable but with difficulty - the opinion of $26 \%$ of men and $10 \%$ of women, which is about $15 \%$ of the total number respondents.

Simultaneously, all $100 \%$ of respondents fully recognise the positive influence of self-employed freelancer activities in the studied sphere on the Republic's territory on the education of children.

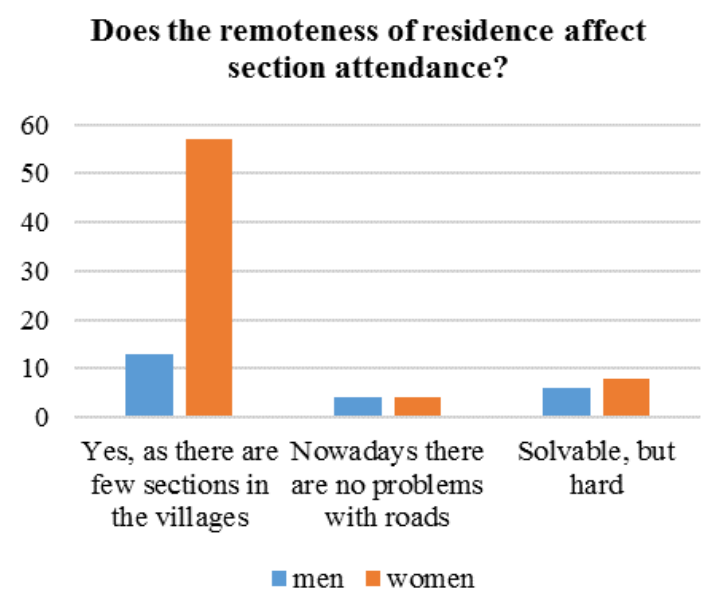

Figure 3 The influence of the habitation remoteness of rural residents on the attendance of sections.

The basic conclusions include village inhabitants recognise the importance and significance of cultural and educational sections; the demand for them is high. Still, their choice is limited and represented by government agencies free of charge sections and services promoted and rendered. In the surveyed settlements, paid services in this sphere with sufficient demand are absent, first of all, due to the low paying capacity of potential users and their small number.

\subsection{The study of parents`attitude to the activity of self-employed freelancers}

While studying the parents`opinion, 387 respondents took part. It was suggested to solve the following list of questions:

- Definition of the demand level for these sections among residents;

- Definition of the degree of satisfaction with activities of sections;

- Definition of the most problematic points arising for parents;

- Analysis of opinion on the activities of sections in the Republic.

Analysing the personal data, the obtained results allow us to make several conclusions.

The largest percentage $(56 \%)$ falls on junior school pupils (1-4 forms), which was enough expected because it is the age when most children begin to try themselves in various activities. The next is middle school pupils (58 forms) - $27 \%$ of surveyed, pre-school age (under 7) $13 \%$ and the lowest percentage falls on senior school pupils (9-11) - 4\%. (see fig. 4) The low involvement of senior school pupils into out-of-school activities can be 
explained by free time limitations and severe loads arising in the period of individual training for final examinations.

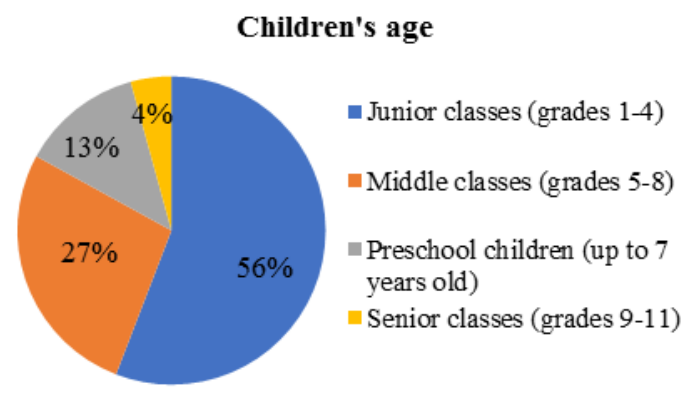

Figure 4 Attendance of sections depending on age.

How many sections does the child attend? Children attend only one section - $37 \%$ of surveyed, two sections - $41 \%$, more than two sections - $22 \%$. According to these data, we can conclude that most children attend on average 1-2 sections. The detailed study of this issue made it possible to mark the basic model with two sections which, as a rule, can be mastered by every child:

1. Sports section to keep your child in good physical shape. For example, individual or team sports, dancing, aerobics.

2. Studio or section oriented to the development of some creative or mental abilities. Someone may be interested in drawing, someone - playing a musical instrument, and someone digs in foreign languages with great pleasure or, for example, designs robots.

As was already mentioned, this is a particular base which parents start from. However, some children can attend three, four and perhaps even five sections with pleasure and success (although it is already a critical figure which should not be exceeded in most cases). While some children, on the contrary, even two kinds of additional activities "pull" heavily (in such a case, it may be reasonable to stay with only one section).

Satisfaction from activities. When asked: whether parents are satisfied from activities, most respondents $(51 \%)$ replied in the positive, $27 \%$ are not quite satisfied with the quality of conditions for activities but believe that a child shall be involved in something and $22 \%$ are yet undecided.

When surveying, we were faced with the fact that many parents and their children are still searching and often change sections going from one to another to find the one that will satisfy them completely.

What results are expected by parents? Parents` expectations from after-school programs and sections are different: some have hopes for outstanding achievements; others only want to keep the general development of their child. What results are expected by parents we surveyed? The most percentage $(40 \%)$ of surveyed parents expect high results which will allow their child to be professionally involved in the future, $35 \%$ do not dream of high results and keep the general development in this sphere, $25 \%$ only accustom to work ethic, discipline without occupational objectives.

Arising difficulties. Also, the questionnaire included a question about parents' difficulties, $44 \%$ of respondents are satisfied in full, $32 \%$ have financial difficulties due to high pay. Often the attendance of modern studios is rather expensive. And even if the section itself is free of charge, it is necessary to pay for expendable materials, equipment, costumes and so on (depending on the orientation of activities). Consequently, the more additional activities, the more expenses. $24 \%$ of respondents answered that plenty of time is expended for taking the child to the section. Parents' free time plays an important role. It is often necessary to take, drive the child to chosen sections, and attend some reporting events. All these things require free time, but modern parents have it less and less. This is one more, rather significant problem.

The importance of the section and coterie location. When asked: "Whether is it reasonable to move such activities to the school territory?" Over half $(60 \%)$ of respondents believe that: yes, because it is closer to home, children will be able to walk themselves and it will make their life easier, 34\% discern no difference and $6 \%$ believe that it has no sense, because it is the likelihood that this could adversely affect the quality of services.

Many parents believe that sections opened at school are more convenient, because they can solve one of the critical problems - the lack of time to take the child to the section.

Paid and free sections. When asked: what section would respondents prefer if they had to select, $37 \%$ answered that no difference, $32 \%$ would prefer paid, private sections and $31 \%$ - free sections at school.

In Russia, more and more sections become paid, and this prevents children from getting additional education. Moreover, only every fifth child in the country is trained for free of charge. And in rural areas, more than a third of schoolchildren do not go to any sections. For Russia's whole, the share of free services in the field of additional activities is only $36 \%$. Parents complain that the family budget does not allow them to pay for extracurricular activities, and free classes offer uninteresting programs to children. This is quite understandable because, in Russia, it is impossible to speak unambiguously about the effectiveness of the activities of institutions designed to increase the value of an individual as a worker who increases the country's welfare. The high social and economic stratification by regions allows the population to invest in their development a different amount of funds [8, pp.6-10]. In the past year and a half, the share of paid services in additional education for children has grown in 
Russia by $8 \%$ - from $54 \%$ to $62 \%$. But the number of children attending the additional activities from the end of 2018 does not change: every fifth child has no activities in addition to school lessons.

\subsection{Profile of freelancers - "self-made" involved in the self-programmed sphere of educational and cultural activities with children}

As a part of the study, the profile of these "self-made" engaged in the self-programmed sphere of educational and cultural activities with children was formed. At the early stages of our study, we believe with a high share of confidence to see people interested, first of all, in the commercial component of expectations from the business. In this context, the question was asked: who does the community trust education of the younger generation and what the state must neutralise harmful components in the name of the future. However, the obtained results at the first stage of the study, namely studying the specific and unique character of selfemployed persons in the cultural and educational sphere, did not confirm our expectations. Our primary hypothesis was invalidated. We saw people who were literate, active and nationally-minded. We saw individuals with sufficiently high human potential, with subject-oriented education and appropriate experience in required spheres, the best moral and ethical qualities characterise them.

The heart of the general idea served as the impact of creating own "creative" business, comes from the need to do the favourite work that has special demands in the population, because it is the basis for the development of any civilised society.

\subsection{Unregistered employment in this area}

In this area (self-employment), the economic entities that are not adequately registered to carry out activities. The latent character of their activities results in legal violations. In terms of their size and scale exceeding the income that "employed" people receive from their activities, institutional traps and expenses are critical for legal violations.

The study of the specific nature of activities, nature and reasons being the basis for forming their unregistered nature, is the hot topic of research in employment to determine state policy's effective directions.

Self-employed freelancers said that the main constraint on activity was lack of support from the state, both financial and creating conditions for functioning. Social protection measures carried out in the Republic and including more than 100 types of support for families with children and low-income population [8, pp.74-76] did not affect the studied social and economic relations, which, in our opinion, is one of the constraints of human potential concerning its effective formation.

Implemented state projects and programs in the territory of the Republic of Kalmykia, supporting small and medium-sized businesses and the social sphere, presupposing the creation of conditions for the development of human capital, which, according to Y. Ben-Porath "is a special fund that performs the functions of producing labour resources in social units" [9, pp. 129154], are free of participation of such economic entities as self-employed persons.

\section{CONCLUSION}

Evaluation and analysis of the results obtained allow us to draw the following conclusions:

1. Express surveys in the form of questionnaires, and expert interviews are effective methods for studying the reliability of socially significant processes and phenomena

2. The need to form the system for monitoring the activities of this category of citizens as part of the project for the development of human capital is the critical task;

3. The critical scientific field serves as an extension of studies of this type of employment's effect to neutralise negative and consider the possibility of multiplication of positive effects.

The most significant recommendations developed during the discussion of the results of the study include the following:

1. Amendments to the laws and regulations governing measures of state support for small businesses, to ensure their availability to self-employed; including information and consulting services

2. Adoption of the legal act that clearly defines the legal status of persons of this category of economic activity, which will allow, among other things, to solve the problem of ensuring social protection of selfemployed citizens;

3. Creation of the special form of self-regulation of the studied type of activity to maintain its high level, observe business ethics and build the special form of interaction with the State

\section{REFERENCES}

[1] Russian labour market: trends, institutions, structural changes, Report of CeTI and LIRT NRU HSE for CSR, M.: NRU HSE, 2017, p. 148.

[2] New forms of employment [Electronic resource] Retrieved from: //tass.ru $>$ Economy and business//vcot.info ${ }^{n}$ ews...vnii...dmitrij- 
platygin...na...seti...briks (date of access: 05/18/2020).

[3] B.V. Dordzhieva, The agrarian archaic of the disregarded economy of the Republic of Kalmykia, Fundamental research 3-3 (2014) 547-549.

[4] T.W. Schultz, Investment in Human Capital: The Role of Education and Research. N.Y., 1971.

[5] M. Arellano, Panel Data Models: Recent Developments in J. Heckman and E. Leamer (eds.), M. Arellano, B. Honore, Handbook of Econometrics Vol. 5 (2001) 58-72.

[6] E.S. Boldyreva, A.B. Mushaeva, Implementation of cultural and educational projects of selfemployment as a factor in personality formation, Factors of Human Capital Formation: Analysis and Development Prospects, Kalmyck national university, Elista, 2019, pp. 33-35.

[7] T.V. Burlutkin, Assessment of the development of human capital in the Republic of Kalmykia, Vectors of human capital development in the system of ensuring the region's economic security in postpandemic reality Kalmyck national university, Elista, 2020, p. 145.

[8] O.B. Dordzhieva, E.B. Boldyreva, Implementation of measures of state family policy to promote family values and the public prestige of the family lifestyle in the Republic of Kalmykia, Materials of the III All-Russian scientific-practical conference with international participation "Social dynamics of the population and sustainable development", Moscow State University named M.V. Lomonosov, Moscow, 2020, p. 244.

[9] Ben-Porath Y. The Production of Human Capital over Time, W. Lee Hansen, editor, Education, Income, and Human Capital, NBER, 2016, pp. 129154. 